\title{
Enzymolysis of Glomerular Immune Deposits In Vivo with Dextranase/Protease Ameliorates Proteinuria, Hematuria, and Mesangial Proliferation in Murine Experimental IgA Nephropathy
}

\author{
Loreto Gesualdo, Steven Ricanati, Medhat O. Hassan, * Steven N. Emancipator, and Michael E. Lamm \\ Institute of Pathology and the *Department of Pathology, Veterans Administration Hospital, \\ Case Western Reserve University, Cleveland, Ohio 44106
}

\begin{abstract}
The therapeutic effects of saccharolytic and proteolytic enzymes were investigated in models of IgA nephropathy. Mesangial glomerulonephritis was induced in mice by intravenous injection of preformed soluble immune complexes of dextran sulfate and either IgA (J 558) or IgM (MOPC $104 \mathrm{E})$ antidextran MAb (passive model) or by immunization with DEAE dextran (active model). In the passive model, only $30-40 \%$ of dextranase-treated mice given IgA or IgM immune complexes had mesangial Ig or dextran deposits, compared with $100 \%$ of saline-treated controls $(P<0.01)$. There was no significant difference in mice given only protease. In the active model, dextranase and protease separately each reduced glomerular dextran and $\mathrm{C} 3$ deposits, and hematuria $(P<0.01)$. Dextranase also reduced the glomerular IgA deposits $(20$ vs. $100 \%$ of saline-treated mice) and the frequency and severity of mesangial matrix expansion (both $P<0.02$ ), but did not reduce the modest IgG or IgM codeposits. Protease reduced IgG and IgM deposits, proteinuria and mesangial hypercellularity compared with saline $(P<0.02)$, but did not diminish IgA, and had no effect on mesangial matrix expansion. The combination of dextranase plus protease attenuated all components of glomerular injury as judged by clinical and pathologic parameters, but inactivated dextranase plus inactivated protease had no effect on any parameter. We conclude that enzymatic digestion of antigen and antibody can reduce immune deposits, mesangial proliferation, proteinuria, and hematuria in experimental glomerulonephritis. (J. Clin. Invest. 1990. 86:715-722.) Key words: glomerulonephritis $\bullet$ therapy $\bullet$ immune complexes $\bullet$ immune complex disease
\end{abstract}

\section{Introduction}

Immune complexes play a central role in initiation and propagation of glomerulonephritis. Reasoning that enzymatic dissolution of immune complexes could diminish their mass within glomeruli and thereby attenuate disease, we previously dem-

Address reprint requests to Dr. Michael E. Lamm, Institute of Pathology, Case Western Reserve University, 2085 Adelbert Road, Cleveland, $\mathrm{OH} 44106$.

Parts of this work were presented at the American Society of Nephrology meeting in San Antonio, TX, 11-14 December 1988 and published in abstract form (Kidney Int. 1989. 35:347a.).

Received for publication 11 August 1989 and in revised form 17 April 1990

J. Clin. Invest.

(c) The American Society for Clinical Investigation, Inc.

0021-9738/90/09/0715/08 $\$ 2.00$

Volume 86, September 1990, 715-722 onstrated that parenteral injection of proteolytic enzymes capable of digesting both the antigen and antibody components of immune complexes can reduce the amount of complexes in glomeruli of both rats and mice with passive serum sickness glomerulonephritis (1). Similar observations were subsequently reported in rabbits by Steffen and Menzel (2). When such therapy was extended to rats with passive Heymann nephritis, we observed the prevention and even reversal of proteinuria, the clinical hallmark of this model of membranous glomerulonephritis (3). Active Heymann nephritis has also been effectively treated with intravenous pepsin (4). Recently, we showed that protease therapy can reverse not only severe proteinuria but also the hyperlipidemia associated with the nephrotic syndrome in a model of active serum sickness induced in rats by immunization with cationic bovine gammaglobulin (5).

We considered whether enzyme therapy could be of benefit as well in proliferative glomerulonephritis characterized clinically by hematuria, and to what extent cleavage of antigen and antibody separately by different classes of enzyme would be effective. These questions can be approached in models of IgA nephropathy. IgA nephropathy, an immune complex glomerulonephritis, is the most prevalent form of glomerulonephritis worldwide $(6,7)$. It typically manifests clinically as hematuria, which may be accompanied by proteinuria, renal insufficiency, and hypertension. IgA nephropathy is recognized pathologically by a proliferation of cells and expansion of matrix within the glomerular mesangium, associated with electron dense mesangial immune deposits, which by immunofluorescence contain IgA and C3 and lesser amounts of IgG and $\operatorname{IgM}(6,7)$.

A number of models of $\operatorname{IgA}$ nephropathy are available in rats and mice, each emphasizing different aspects of the disease (8). Among these, chronic immunization of mice with dextran elicits a glomerulonephritis that closely resembles clinically and pathologically typical cases of IgA nephropathy in humans (9-11). We considered this model of IgA nephropathy an ideal system for our purposes because of its clear, objective clinical and pathologic signs of disease and because the polysaccharide antigen and protein antibody components of the immune complexes involved can be independently cleaved by different classes of enzyme. Use of a saccharidase to dissolve glomerular immune complexes containing polysaccharide antigen in vivo also serves as an additional control to ensure that our prior success with enzyme therapy of experimental glomerulonephritis was not due to some nonspecific systemic proteolytic action.

\section{Methods}

Induction and treatment of passive IgA nephropathy. Soluble immune complexes of dextran sulfate (500 kD; Sigma Chemical Co., St. Louis, 
MO) and murine monoclonal IgA anti- $\alpha 1 \rightarrow 6$ glycoside (J558; Litton Bionetics, Kensington, MD) or IgM anti- $\alpha 1 \rightarrow 3$ glycoside (MOPC 104 $\mathrm{E}$; Litton Bionetics) were prepared at threefold antigen excess (26.5 $\mu \mathrm{g}$ dextran/mg J558; $22.0 \mu \mathrm{g}$ dextran/mg MOPC $104 \mathrm{E}$ ). Complexes containing $3 \mathrm{mg}$ antibody were injected into $20 \mathrm{-g}$ male Swiss-Webster mice (Charles River Breeding Laboratories, Lexington, MA) via tail vein (9). $1 \mathrm{~h}$ later, after maximal deposition of complexes, mice were injected intraperitoneally with five doses of either saline, $0.1 \mathrm{mg}$ dextranase, or $0.05 \mathrm{mg}$ nagarse (subtilisin) plus $0.1 \mathrm{mg}$ chymopapain, at 10-min intervals. These doses were nontoxic in pilot studies. All enzymes were purchased from Sigma Chemical Co. Mice were killed $1 \mathrm{~h}$ after the last enzyme injection. The dextranase had $<5$ millicaseinolytic units per $\mathrm{mg}$ protein, as opposed to the proteases, which had 2,000-7,000 $\mathrm{mU} / \mathrm{mg}$ protein (12).

Induction and treatment of active IgA nephropathy. 35-g male Swiss-Webster mice (Charles River Laboratories) were divided into five groups: 4 groups ( 37 mice total) were given $1 \mathrm{mg}$ i.p. $500 \mathrm{kD}$ DEAE-dextran (Sigma Chemical Co.) in PBS, pH 7.4, on days 1, 7, and 10 followed by injections of $1 \mathrm{mg}$ i.v. of dextran thrice weekly until day 75 , for a total of $30 \mathrm{mg}(10,11)$. Group 5 (control, 10 mice) received saline. Randomly selected immunized mice were then treated with either dextranase $(0.5 \mathrm{mg}$ i.v.), chymopapain plus nagarse $(0.38 \mathrm{mg}$ plus $0.18 \mathrm{mg}$ i.p.), a combination of dextranase intravenously and protease intraperitoneally, or saline, twice a day for $5 \mathrm{~d}$. The enzyme doses were the maximum that did not elicit histological or clinical evidence of toxicity in pilot studies. After the last enzyme injection, all mice were placed in individual metabolic cages and urine was collected for $24 \mathrm{~h}$. Urine was tested with Hemastix and Albustix (Ames Division, Miles Laboratories, Elkhart, IN) and centrifuged. Supernatants were assayed for protein by turbidimetry in $3 \%$ sulfosalicylic acid (3). Sediments were used for microscopic determination of the number of erythrocytes in three high-power $(40 \times)$ fields for each mouse. Mice were subsequently killed under ether anesthesia and blood was collected from the aortas. Serum creatinine was measured by Jaffe's picric acid method (3).

Induction of active IgA nephropathy and treatment with inactivated enzymes. 24 mice were immunized with dextran as described above; another 8 mice served as controls. After completion of immunization, a pretreatment urine collection (initial) was performed, and hematuria and proteinuria were determined (see below). The 21 hematuric and the 3 nonhematuric mice were separately randomly allocated to 3 groups ( 8 mice per group), which were treated either with saline, a mixture of protease and dextranase, or a mixture of inactivated protease and inactivated dextranase (see below). Saline and active enzymes were administered as described above. Inactivated enzymes were given at the same mass, concentration, route, and times as the active enzymes. There were no differences among the immunized groups with respect to severity or frequency of initial hematuria or proteinuria. After $5 \mathrm{~d}$ of treatment, all mice were housed in individual metabolic cages for urine collection and killed for morphologic and serologic study as described below.

Morphology. After the mice were killed, one kidney from each was divided for light, immunofluorescence, and electron microscopy. Snapfrozen samples of renal cortex, cryostat sectioned at $4 \mu \mathrm{m}$, were stained with fluoresceinated IgG fractions of goat antisera specific for mouse IgA, IgM, IgG, or C3 (U. S. Biochemical Corp., Cleveland, OH) by direct immunofluorescence and scored semiquantitatively in doubleblind fashion $(1,3)$. Among mice given immune complexes passively, no direct staining for IgM was observed in mice given $\mathrm{J} 558$, and no direct staining for IgA was observed in mice given MOPC $104 \mathrm{E}$. Hence, dextran antigen could be detected with indirect staining; sections were incubated with $100 \mu \mathrm{g} / \mathrm{ml}$ of either MOPC $104 \mathrm{E}$ followed by FITC goat anti-mouse IgM for mice given J558-containing immune complexes, or $100 \mu \mathrm{g} / \mathrm{ml}$ of J558 followed by FITC goat antimouse IgA for mice given MOPC 104 E-containing complexes. Dextran antigen was detected in renal deposits of mice with active IgA nephropathy by an immunoperoxidase technique. Briefly, $10 \mathrm{mg} 5$ hydroxysuccinimido-biotin (Sigma Chemical Co.) in $100 \mu \mathrm{l}$ DMSO was added to $5 \mathrm{ml}$ of a solution of MOPC $104 \mathrm{E} \mathrm{IgM} \mathrm{anti-dextran} \mathrm{in}$ $0.1 \mathrm{M}$ sodium carbonate/bicarbonate buffer, $\mathrm{pH} 8.5$. After $4 \mathrm{~h}$ incubation at room temperature, the mixture was dialyzed at $4^{\circ} \mathrm{C}$ over $24 \mathrm{~h}$ against six changes of carbonate buffer. For immunoperoxidase staining, air-dried acetone-fixed $4 \mu \mathrm{m}$ cryostat sections were incubated for $30 \mathrm{~min}$ in $0.3 \% \mathrm{H}_{2} \mathrm{O}_{2}$ in methanol to inactivate endogenous peroxidase, and the sections were overlaid with $100 \mu \mathrm{g} / \mathrm{ml}$ biotinyl MOPC-104 E and incubated at $4^{\circ} \mathrm{C}$ overnight. After washing thrice in PBS, a solution of peroxidase-conjugated streptavidin (Vector Laboratories, Burlingame, CA) diluted 1:500 was applied to the sections and incubated for $1 \mathrm{~h}$ at room temperature. After further washing, 750

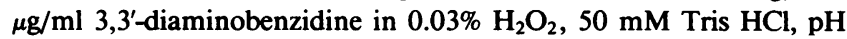
7.5 , was applied for $8 \mathrm{~min}$. After final washing, coverslips were mounted with $50 \%$ glycerol in PBS. Sections were semiquantitatively scored by two observers in double-blind fashion.

Sections of renal cortex fixed in $10 \%$ formalin were embedded in paraffin, cut at $2 \mu \mathrm{m}$, and stained with PAS reagent $(1,3)$. Expansion of mesangial matrix was scored semiquantitatively $(0$, normal; $1+$, segmental increases in matrix revealed as widened mesangial stalk; $2+$, global increases in matrix with some encroachment on capillary lumens; $3+$, conspicuous widening of mesangial stalk with decrease in capillary lumen). Mesangial hypercellularity was scored semiquantitatively as well $(0$, normal, three or fewer cell nuclei per mesangial area; $1+$, mild, four to six nuclei per mesangial area; $2+$, moderate, four to six nuclei in most mesangial areas, but seven or more in others; $3+$, severe, seven or more nuclei per mesangial area). Two observers independently assessed morphologic changes in a double-blind protocol. In addition, total glomerular area, matrix area and glomerular cellularity were quantified in 10 randomly selected glomeruli from each mouse by computer morphometry (Cue Image Analysis System, Olympus Corp., Columbia, MD). Cubes of cortex, $1 \mathrm{~mm}$ in each dimension, were fixed in $2.5 \%$ glutaraldehyde in $0.1 \mathrm{M}$ sodium cacodylate, postfixed in $1 \%$ $\mathrm{OsO}_{4}$, and embedded in Spurr's epoxy (Polysciences, Inc., Warrington, PA). Ultrathin (50-70 nm) sections were picked up on uncoated copper grids, and stained with uranyl acetate and lead hydroxide. Coded grids were examined in a JEOL JEM 100 EX microscope. Mesangial matrix, cellularity, and immune deposits were semiquantified by examination of coded specimens (3).

Inactivation of dextranase and proteases. $3.4 \mathrm{mg} / \mathrm{ml}$ dextranase was inactivated by incubation in an equal volume of $2 \mathrm{mM}$ N-bromosuccinimide (Sigma Chemical Co.) at $\mathrm{pH} 6,37^{\circ} \mathrm{C}$ for $30 \mathrm{~min}$ (13). The mixture was dialyzed extensively against $0.1 \mathrm{M}$ potassium phosphate, pH 6.0. Active $(0-44 \mu \mathrm{g} / \mathrm{ml})$ and inactive $(0-440 \mu \mathrm{g} / \mathrm{ml})$ dextranase solutions at varying final concentrations were incubated with $2 \%$ neutral dextran $\left(500 \mathrm{kD}\right.$ ) in $0.1 \mathrm{M}$ potassium phosphate, $\mathrm{pH} 6.0,37^{\circ} \mathrm{C}$ for $30 \mathrm{~min}$. Maltose release was measured by adding $1 \mathrm{ml}$ of the reaction volume to $1 \mathrm{ml} 1 \%$ dinitro-salicylic acid (Eastman Kodak Co., Rochester, $\mathrm{NY}$ ) in $1.43 \mathrm{M}$ sodium potassium tartrate, $0.4 \mathrm{~N}$ sodium hydroxide, and by incubating for $15 \mathrm{~min}$ at $100^{\circ} \mathrm{C}$. After cooling and diluting 1:6 in water, the optical density was read at $540 \mathrm{~nm}$ and interpolated into a standard curve obtained by developing solutions of varying concentrations of maltose (Sigma Chemical Co.) in dinitrosalicylic acid. Dextranase activity, expressed as micromoles maltose released per minute (13), was $24.5 \mathrm{U} / \mathrm{mg}$ protein for the active enzyme and 0.32 $\mathrm{U} / \mathrm{mg}$ protein for inactivated dextranase ( $99 \%$ inhibition).

Chymopapain and nagarse were inactivated by dissolving each enzyme in $6 \mathrm{M}$ guanidine $\mathrm{HCl}, 10 \mathrm{mM}$ Tris $\mathrm{HCl}, \mathrm{pH} 7.0$, to a final concentration of $10 \mathrm{mg} / \mathrm{ml}(14,15)$. After bubbling nitrogen through the solutions, DTT (International Biotechnologies, Inc., New Haven, CT) was added to a final concentration of $30 \mathrm{mM}$. The mixture was then incubated at $37^{\circ} \mathrm{C}$ for $3 \mathrm{~h}$ and iodoacetamide was added to a final concentration of $33 \mathrm{mg} / \mathrm{ml}$; an equal mass of solid Tris base was added simultaneously to prevent rapid $\mathrm{pH}$ change (15). The $\mathrm{pH}$ of the mixture was adjusted to 8.0 with $1 \mathrm{M}$ Tris base. After $30 \mathrm{~min}$ at $4^{\circ} \mathrm{C}$, the solution was exhaustively dialyzed against PBS. Active $(0-500 \mu \mathrm{g} / \mathrm{ml})$ and inactive $(0-1,500 \mu \mathrm{g} / \mathrm{ml})$ chymopapain at varying concentrations were incubated at $25^{\circ} \mathrm{C}$ for $60 \mathrm{~min}$ with $\mathrm{N}-\alpha$ benzoyl-DL-arginine $p$-nitroanilide (Sigma Chemical Co.) and active $(0-500 \mu \mathrm{g} / \mathrm{ml})$ and 
inactive $(0-1,500 \mu \mathrm{g} / \mathrm{ml})$ nagarse at varying concentrations were incubated with $N$-acetyl-L-alanine $p$-nitroanilide (Sigma Chemical Co.) at $25^{\circ} \mathrm{C}$ for $60 \mathrm{~min}$. The chromogenic peptide substrates were first dissolved at $43.5 \mathrm{mg} / \mathrm{ml}$ in DMSO (Sigma Chemical Co.) and then diluted 1:10 in PBS just before enzyme addition. The change in the optical density at $405 \mathrm{~nm}$ per minute, divided by the micromolar extinction coefficient of $p$-nitroaniline $\left(5.495 \times 10^{-3}\right)$ was taken as the enzymatic activity. Active chymopapain had a specific activity of $0.957 \mathrm{U} / \mathrm{mg}$, whereas inactivated chymopapain had $0.096 \mathrm{U} / \mathrm{mg}$ ( $90 \%$ inhibition). Active nagarse had a specific activity of $1.67 \mathrm{U} / \mathrm{mg}$, whereas inactivated nagarse had $<0.034 \mathrm{U} / \mathrm{mg}$ ( $98 \%$ inhibition).

Statistical analysis. Count and semiquantitative data were compared among groups with the chi-squared test with the Fisher-Yates correction always applied. Quantitative data were compared by analysis of variance, with multiple inferences by Fisher's protected $t$ test.

\section{Results}

\section{Passive IgA nephropathy model}

All 10 mice injected with soluble preformed IgA-dextran immune complexes and sham-treated with saline had granular mesangial deposits of IgA and dextran, but no detectable IgM or IgG; in contrast, only 3 of 10 mice given identical doses of IgA immune complexes but treated with dextranase had IgA deposits (Fig. $1 A)\left(\chi^{2}=7.9 ; P<0.01\right.$ vs. saline-treated mice) and only 4 mice had detectable dextran deposits $\left(\chi^{2}=6.0 ; P\right.$ $<0.02$ vs. saline). Protease treatment did not significantly alter either IgA or dextran deposits. Among 10 mice given soluble preformed IgM-dextran immune complexes and treated with saline, all 10 had granular mesangial IgM and dextran (Fig. 1 $B$ ), without IgA or IgG. Again, dextranase treatment signifcantly reduced mesangial immunoglobulin (IgM) and dextran (both positive in only 4 of 10 mice) $\left(\chi^{2}=6.0 ; P<0.02\right.$ vs. saline-treated mice). Protease treatment had no effect. No group exhibited significant $\mathrm{C} 3$, and the mild increase in PASpositive mesangial matrix seen in all mice given immune complexes did not vary among the groups. None of eight normal control mice had any IgA, IgM, or dextran deposits.

\section{Active IgA nephropathy model}

Morphology. Immunofluorescence microscopy (Figs. 2 and 3) revealed bright granular mesangial staining for IgA in all 10 dextran-immunized mice treated with saline; IgM was present in 9 of these mice and IgG in 8, both with parallel mild to moderate staining intensity in the same distribution, appreciably less intense than the IgA deposits. 6 of these 10 mice had moderately intense mesangial C3 as well. Moderate to intense staining for dextran was demonstrable by immunoperoxidase in all 10 immunized mice treated with saline. None of the nonimmune, age-matched control mice had deposits of Ig, C3, or dextran (all $\chi^{2} \geq 6 ; P<0.02$ ). By light microscopy (Table I, Fig. 4), there was generally moderate mesangial hypercellularity and moderate to marked expansion of mesangial matrix in all immunized saline-treated mice compared with nonimmune controls $\left(\chi^{2}=16.2 ; P \leq 0.001\right)$. Mean mesangial matrix area in saline-treated nephritic mice was higher than in controls, whether normalized for total glomerular area or not (both $P<0.001$ ). Likewise, the number of nuclei was $60 \%$ higher in nephritic mice versus controls $(P<0.001$ whether normalized for glomerular area or not). No extracapillary or endocapillary proliferation was observed and changes were confined to the mesangium. Tubular basement membranes of immunized mice were expanded with PAS-positive material as well, and occasional vacuoles were evident in glomerular and tubular cells (Fig. 4), but no tubulointerstitial infiltration or fibrosis was evident. Ultrastructurally, immunized mice had numerous, variably sized but generally large vacuoles containing inclusions of variable density in podocytes, endothelial cells, and mesangial cells, and electron-dense and -lucent deposits in subendothelial and mesangial sites (not shown) similar to those previously described (11).

Clinical features. Immunized mice with IgA nephropathy were visibly sluggish and had rumpled fur compared with nonimmune controls. Hematuria (Table II), manifest as occult blood detected by dipstick and as more than nine RBCs per high-power field by microscopic examination of urinary sediment, was present in the urine collected over the day before killing in all 10 immunized mice, but in none of the 10 nonimmune controls $\left(\chi^{2}=16.2 ; P \leq 0.001\right)$. The increased urinary protein excretion in immunized mice $(1.51 \pm 0.23 \mathrm{mg} / 24$ h) was nearly double that in nonimmune control mice $(0.83 \pm 0.17 \mathrm{mg} / 24 \mathrm{~h} ; t=2.7 ; P<0.025)$. In addition, renal insufficiency was manifest in immunized mice treated with saline by an increase in serum creatinine $(0.33 \pm 0.05 \mathrm{mg} / \mathrm{dl})$ compared with normal controls $(0.15 \pm 0.02 \mathrm{mg} / \mathrm{dl} ; t=3.7 ; P$ $<0.005)$.

Dextranase therapy. Dextranase given to immunized mice for five days reduced the frequency of glomerular IgA ( 2 of 10 mice) and $\mathrm{C} 3$ ( 1 of 10 mice) compared with immunized mice given saline (Figs. 2 and 3$)\left(\chi^{2}=10.2 ; P<0.005\right.$ for $\operatorname{IgA} ; \chi^{2}$ $=3.5 ; P<0.1$ for $\mathrm{C} 3$ ). 7 of 10 dextranase-treated mice lacked dextran deposits, as opposed to strongly positive dextran in 10 of 10 nephritic mice treated with saline $\left(\chi^{2}=7.9 ; P<0.01\right)$. However, 7 of 10 dextranase-treated immunized mice had moderate mesangial IgG, and 8 of 10 had IgM, which was no different from the incidences in saline-treated immune mice. Dextranase significantly reduced the hypercellularity and
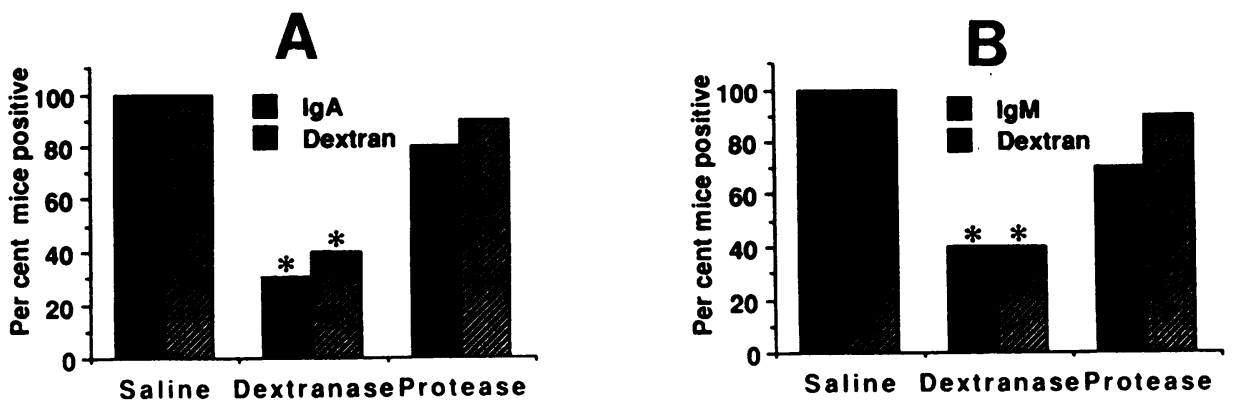

Figure 1. Glomerular immunofluorescence. Dextranase, but not protease, significantly $\left({ }^{*} P<0.02\right)$ reduced glomerular immune deposits formed in mice given preinjections of soluble immune complexes of dextran sulfate antigen and either $\operatorname{IgA}(A)$ or IgM (B) MAb. All control mice given saline instead of enzyme had glomerular antigen and antibody deposits. 


\section{$\lg A$}
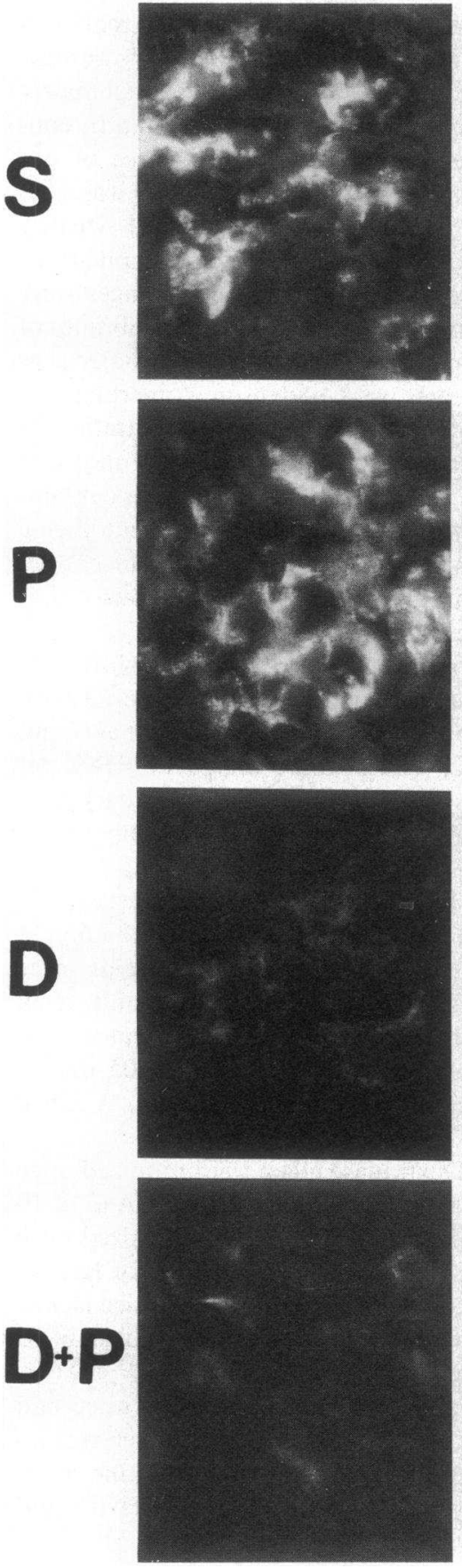

$\lg M$
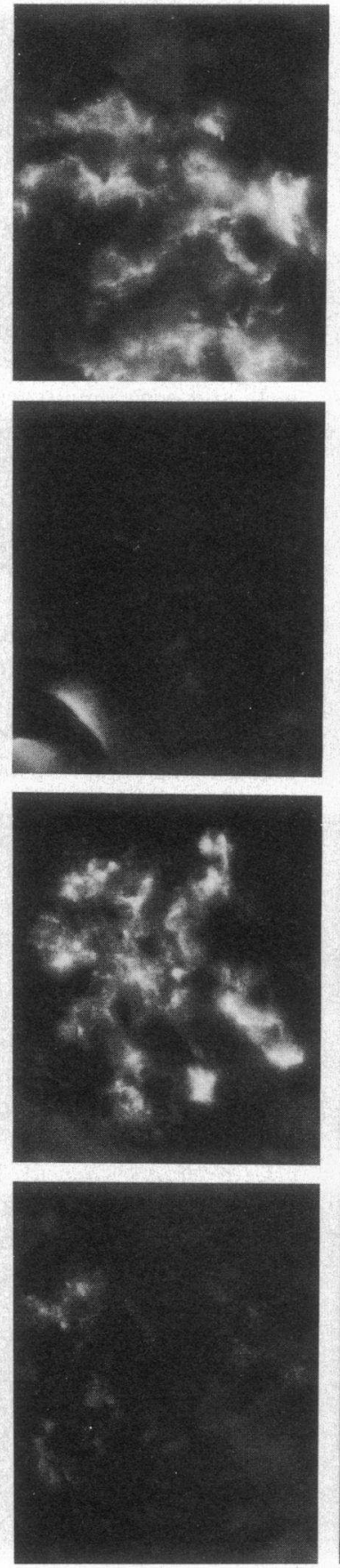
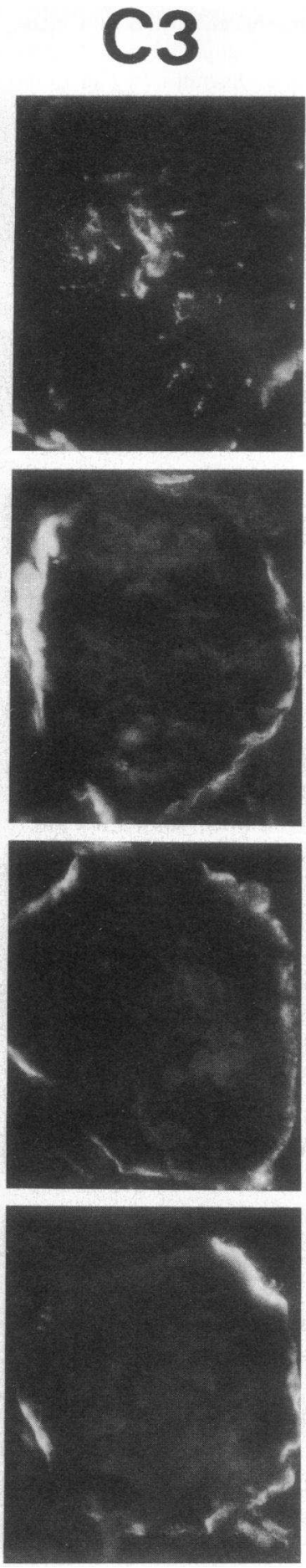

Figure 2. Immunofluorescence micrographs. Representative sections of glomeruli from mice immunized with DEAE-dextran for $10 \mathrm{wk}$ and subsequently treated for $5 \mathrm{~d}$ with saline $(S$, top row), protease $(P)$, dextranase $(D)$, or a combination of dextranase and protease $(D+P$, bottom row) showed that IgA deposits (left column) predominated, and IgG deposits (not shown) were the same as IgM (center column) in distribution, but somewhat less intense than IgM. Both IgG and IgM deposits were less intense than the IgA deposits in the saline-, protease-, and inactivated enzyme-treated mice, but not in control or dextranase-treated mice. IgA deposits were significantly reduced by dextranase, whereas IgM and IgG were removed by protease. Protease and dextranase each diminished intensity of $\mathrm{C} 3$ deposits in the glomeruli (right column) and dextran antigen (not shown) (the peripheral ring of $\mathrm{C} 3$ fluorescence in Bowman's capsule, which is seen in normal mice and is not affected by enzyme, is unrelated to the experiments). The combination of dextranase and protease was effective at removing all immune reactants. See also Fig. 3.
PAS-positive material in mesangial matrix (Fig. 4, Table I) and tubular basement membrane compared with saline-treated immunized mice; only 2 dextranase-treated mice had more than a trace increase in mesangial matrix compared with all 10 treated with saline $\left(\chi^{2}=10.2 ; P<0.005\right)$, and the mean mesangial area in dextranase-treated mice was not different from normals, but $36 \%$ less than in saline-treated nephritic mice $(P$ $<0.001$ ). Hematuria was also significantly reduced by dextranase treatment (Table II); only 6 of 10 mice had any hematuria and none of 10 had more than five RBCs per high-power field whereas all 10 saline-treated mice had more than nine red cells per high-power field $\left(\chi^{2}=16.2 ; P<0.001\right)$. There was no significant difference between dextranase and saline treatment in regard to proteinuria and serum creatinine (Table II).

Protease therapy. Protease treatment of active IgA nephropathy significantly reduced the frequency of the mild to moderate mesangial deposits of both IgG (2 of 9 mice) and IgM ( 1 of 9 mice) compared with saline-treated immunized mice ( 8 of 10 and 9 of 10 , respectively) $\left(\chi^{2}=4.2,8.9 ; P<0.05\right.$, 0.01 ) (Figs. 2 and 3). Although only 1 of 9 protease-treated 


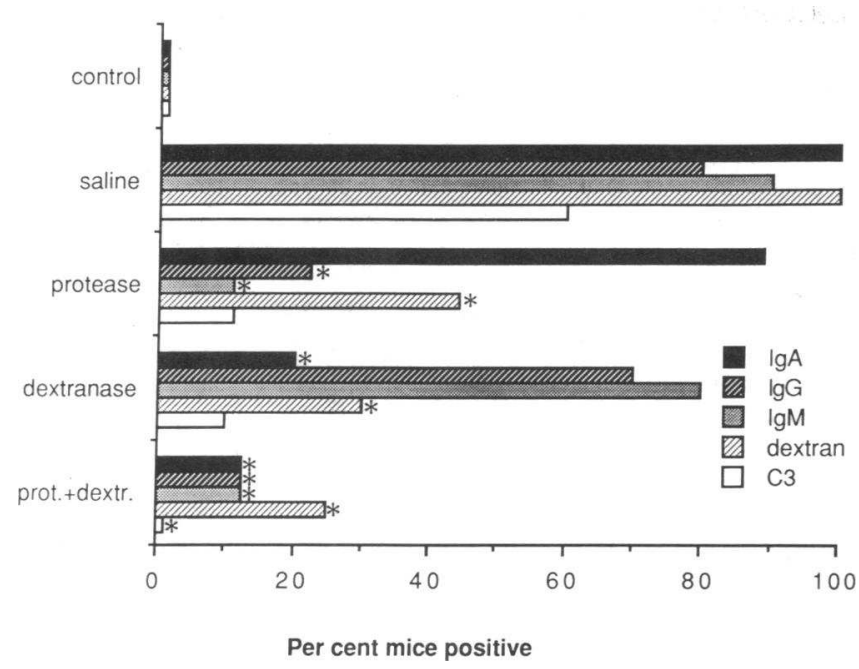

Figure 3. Incidence of glomerular deposits. The frequencies of immunofluorescent deposits of antibody, dextran antigen and complement in normal controls and in mice immunized with DEAE-dextran for $10 \mathrm{wk}$ and subsequently treated for $5 \mathrm{~d}$ with saline, protease, dextranase, or a combination of protease and dextranase are shown. Protease significantly $\left({ }^{*} P<0.05\right)$ reduced the frequency of IgG and IgM antibody and dextran deposits, whereas dextranase significantly reduced $\operatorname{IgA}$ and dextran deposits, compared with saline treatment. The combination of protease and dextranase was extremely effective at reducing the frequency of all immune reactants in glomeruli.

mice had mesangial $\mathrm{C} 3$, this was not significantly different from the 6 of $10 \mathrm{C} 3$ positive saline-treated mice $\left(\chi^{2}=3.0\right)$. Protease by itself was ineffective at reducing glomerular IgA. Protease reduced the incidence of dextran deposits (four of nine mice) relative to saline treatment $\left(\chi^{2}=4.9 ; P<0.01\right)$. The frequency distribution of mice with respect to mesangial matrix expansion in protease-treated mice was intermediate between mice treated with saline and dextranase (Fig. 4, Table I), but the difference in frequency between either of these groups and protease-treated mice was not significant $\left(\chi^{2}=1.8\right.$ and 2.5 , respectively). Mesangial matrix area in proteasetreated mice did not differ from that in saline-treated mice. Protease reduced the extent of mesangial cellularity by $35 \%$ compared with saline-treated mice $(P<0.001)$, a level not significantly different from controls. The incidence of semiquantitative scores showed a trend towards milder prolifera-
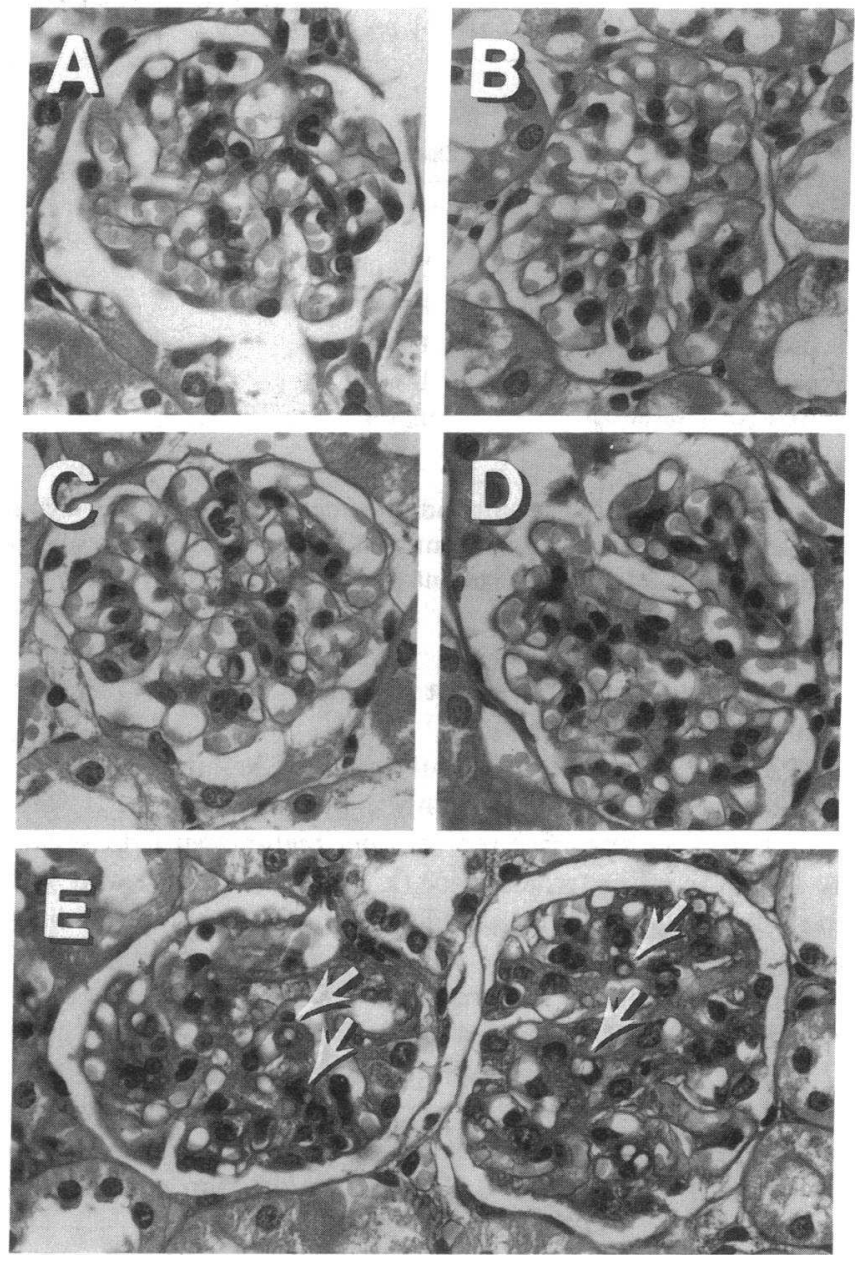

Figure 4. Light micrographs. Representative glomeruli from normal control mice $(A)$ and dextran-immunized mice treated with combined dextranase plus protease $(B)$, dextranase $(C)$, protease $(D)$, or saline $(E)$ reveal that saline-treated mice $(E)$ had moderate to marked expansion of mesangium by PAS-positive matrix accumulation, and generally severe mesangial hypercellularity as opposed to the normal animals $(A)$, with only two to three nuclei per mesangial area. Combined therapy $(B)$ and dextranase alone $(C)$ reduced matrix expansion and mesangial hypercellularity, whereas protease alone $(D)$ reduced only cellularity. Note also that vacuoles (arrows) are present in glomerular cells in mice given saline $(E)$, but are not conspicuous in other groups. See also Table I.

Table I. Effect of Enzyme Therapy on Light Microscopic Changes in Active IgA Nephropathy

\begin{tabular}{|c|c|c|c|c|c|c|c|c|}
\hline \multirow[b]{2}{*}{ Treatment } & \multirow[b]{2}{*}{ Disease status } & \multicolumn{2}{|c|}{$\begin{array}{l}\text { Mesangial matrix } \\
\text { expansion* }\end{array}$} & \multirow[b]{2}{*}{ Area ${ }^{8}$} & \multicolumn{3}{|c|}{ Mesangial hypercellularity ${ }^{\ddagger}$} & \multirow[b]{2}{*}{ Nuclei" } \\
\hline & & $0-1+$ & $22+$ & & 0 & $1+$ & $\geq 2+$ & \\
\hline None & Normal & $10^{\prime}$ & & $26 \pm 5.9^{\pi}$ & $10 \pi$ & & & $2.32 \pm .72^{r}$ \\
\hline Saline & IgAN & & $10^{* *}$ & $42 \pm 5.8^{* *}$ & & 3 & $7^{* *}$ & $3.64 \pm 1.2^{* *}$ \\
\hline Dextranase & IgAN & $8^{\prime}$ & 2 & $27 \pm 6.1^{\prime}$ & & $7^{\prime}$ & 3 & $3.22 \pm .68^{1 * *}$ \\
\hline Protease & IgAN & 3 & 6 & $45 \pm 16^{* *}$ & 2 & 4 & 3 & $2.36 \pm .70^{9}$ \\
\hline Dextranase + protease & IgAN & $7^{9}$ & 1 & $31 \pm 5.9^{1 * *}$ & $7^{\prime}$ & 1 & & $2.94 \pm .80^{\pi * *}$ \\
\hline
\end{tabular}

* Data are number of mice with the indicated semiquantitative degree of matrix increase (see text). ${ }^{\ddagger}$ Data are number of mice with the indicated semiquantitative degree of mesangial cellularity (see text). ${ }^{\S}$ Data are percent total glomerular area occupied by mesangial matrix (mean $\pm 1 \mathrm{SD}$ ). "Data are number of nuclei per $1,000 \mu \mathrm{m}^{2}$ glomerular area in at least 10 glomeruli/animal. 'Significantly different from the group with IgA nephropathy given saline $(P<0.01)$ by chi-squared test for semiquantitative data and by Fisher's protected $t$ test in analysis of variance $(F \geq 31.6)$ for quantitative data. ** Significantly different from the normal control mice $(P<0.01)$ by chi-squared test for semiquantitative data and by Fisher's protected $t$ test in analysis of variance $(F \geq 31.6)$ for quantitative data. 


\begin{tabular}{|c|c|c|c|c|c|c|c|}
\hline \multirow[b]{2}{*}{ Treatment } & \multirow[b]{2}{*}{ Disease status } & \multicolumn{4}{|c|}{ Hematuria* } & \multirow[b]{2}{*}{ Proteinuria $^{*}$} & \multirow{2}{*}{$\begin{array}{c}\text { Serum } \\
\text { creatinine }^{\ddagger}\end{array}$} \\
\hline & & $<3$ & $3-5$ & $6-9$ & $>9$ & & \\
\hline & & & & & & $m g / 24 h$ & $m g / d l$ \\
\hline None & Normal & 10 & & & & $0.83 \pm .17^{\S}$ & $0.15 \pm .02^{\S}$ \\
\hline Saline & IgAN & & & & $10^{\|}$ & $1.51 \pm .23^{\prime \prime}$ & $0.33 \pm .05^{\|}$ \\
\hline Dextranase & $\operatorname{IgAN}$ & $4^{\S}$ & $6^{8}$ & & & $1.38 \pm .18^{\prime \prime}$ & $0.26 \pm .02^{\prime \prime}$ \\
\hline Protease & IgAN & $3^{8}$ & $4^{8}$ & 2 & & $0.91 \pm .20^{\S}$ & $0.26 \pm .02^{\prime \prime}$ \\
\hline Dextranase + protease & IgAN & $7^{\S}$ & $1^{\S}$ & & & $0.63 \pm .14^{\S}$ & $0.25 \pm .04 \|$ \\
\hline
\end{tabular}

* Data are number of mice with indicated number of RBCs per high-power field in urinary sediments from individual mice. ₹ Data are mean \pm SE. 'Statistically significantly different from the group with IgA nephropathy given saline $(P<0.05)$. "Statistically significantly different from the group of normal untreated mice $(P<0.05)$.

tion, but the difference was not significant compared to either saline or control groups.

Protease therapy significantly reduced hematuria relative to mice treated with saline; only 2 of the 9 protease-treated mice had more than five red cells per high-power field versus all 10 of the saline treated mice $\left(\chi^{2}=9.2 ; P<0.01\right)$, and 3 of the 9 protease-treated mice had no increase in urinary erythrocytes compared to normal controls (Table II). Protease also significantly reduced proteinuria to $0.91 \pm 0.20 \mathrm{mg} / 24 \mathrm{~h}$ compared with $1.51 \pm 0.23 \mathrm{mg} / 24 \mathrm{~h}$ in saline-treated nephritic mice $(t=2.3 ; P<0.05)$. Although protease reduced serum creatinine levels relative to saline-treated mice, the difference was not significant, and protease-treated mice had significantly higher serum creatinine $(0.26 \pm 0.02 \mathrm{mg} / \mathrm{dl})$ than normal control mice $(0.15 \pm 0.02 \mathrm{mg} / \mathrm{dl} ; t=2.4 ; P<0.05)$.

Combined dextranase and protease therapy. Mice rendered nephritic by immunization with dextran and treated with both dextranase and protease had dramatic reductions in glomerular IgA, IgG, IgM, and C3 (Figs. 2 and 3). Only 1 mouse evidenced glomerular Ig (all three isotypes), versus 8-10 mice of the 10 given saline $\left(\chi^{2} \geq 5.6 ; P<0.01\right)$, and no treated mouse had glomerular $C 3$ as opposed to 6 of the 10 given saline $\left(\chi^{2}=5.0 ; P<0.025\right)$. Significantly fewer mice given combined therapy had dextran deposits ( 2 of 8 ) compared with the nephritic mice treated with saline (10 of $10 ; \chi^{2}=8.13 ; P$ $<0.01$ ). Light microscopy likewise revealed significant decreases in both the mesangial matrix accumulations and hypercellularity seen in saline-treated immunized mice $(P$ $<0.01$ ) as judged by both distribution of semiquantitative scores and quantitative morphometry (Table I, Fig. 4). Combined protease and dextranase treatment did not influence the intracellular vacuoles or deposits seen ultrastructurally in saline-treated immunized mice.

Combined enzyme therapy was more effective at reducing hematuria than either protease or dextranase alone (Table II); only 1 mouse of the 8 treated with the combined enzymes had hematuria exceeding normal controls, as opposed to all 10 saline-treated mice $\left(\chi^{2}=10.9 ; P<0.001\right)$. Proteinuria was significantly less in mice given combined enzymes $(0.63 \pm 0.14$ $\mathrm{mg} / 24 \mathrm{~h})$ than in nephritic mice treated with saline $(1.51 \pm 0.23$ $\mathrm{mg} / 24 \mathrm{~h} ; t=3.3 ; P<0.01$ ), reaching the levels in normal controls $(0.83 \pm 0.17 \mathrm{mg} / 24 \mathrm{~h})$. Combined therapy, like therapy with protease alone or dextranase alone, did not significantly reduce serum creatinine.

Dependence of therapeutic effect on enzymatic activity. To determine whether the efficacy of the enzymes resides with their lytic capability or with some other effect, a third experiment was performed. In this experiment, mice immunized

Table III. Efficacy of Active vs. Inactive Enzyme (Dextranase plus Protease) Therapy in Active IgA Nephropathy

\begin{tabular}{|c|c|c|c|c|c|c|c|c|}
\hline \multirow[b]{2}{*}{ Treatment } & \multirow[b]{2}{*}{ Disease status } & \multicolumn{2}{|c|}{ Hematuria* } & \multicolumn{2}{|c|}{ Proteinuria $^{\ddagger}$} & \multicolumn{3}{|c|}{ Glomerular morphology ${ }^{8}$} \\
\hline & & Before & After & Before & After & Ig deposits & Matrix expansion & Hypercellularity \\
\hline None & Normal & $0^{\prime \prime}$ & $0^{\prime \prime}$ & $0.76 \pm 0.34^{\| \prime}$ & $0.96 \pm 0.23^{\prime \prime}$ & $13^{\| \prime}$ & $0^{\prime \prime}$ & $0^{\prime \prime}$ \\
\hline Saline & IgAN & $88^{\prime}$ & $86^{\prime}$ & $2.3 \pm 0.85^{\top}$ & $3.2 \pm 1.0^{4 * *}$ & $100^{\pi}$ & $100^{\prime}$ & $100^{\prime \prime}$ \\
\hline Active enzymes & IgAN & $88^{4}$ & $14^{11 * *}$ & $2.3 \pm 1.1^{1}$ & $1.1 \pm 0.47^{11 * *}$ & $0^{\prime \prime}$ & $0^{\prime \prime}$ & $0^{\prime \prime}$ \\
\hline Inactive enzymes & IgAN & $88^{\prime \prime}$ & $71^{\top}$ & $2.1 \pm 0.86^{\pi}$ & $2.3 \pm 0.85^{\prime}$ & $88^{\pi}$ & $88^{\prime}$ & $88^{\star}$ \\
\hline
\end{tabular}

\footnotetext{
* Data are percent mice positive for hematuria before and after the indicated treatment. Final hematuria is based on seven mice in each treated group, since one mouse in each treated group did not develop hematuria before treatment. ${ }^{\ddagger}$ Data are mean $\pm 1 \mathrm{SD}$ of $24 \mathrm{~h}$ urinary protein excretion ( $n=8$ per group) before and after treatment. ${ }^{8}$ Data are percent of eight mice per group with any Ig detectable by IF, or any degree of matrix expansion or hypercellularity by semiquantitative assessment. "Significantly different from saline-treated nephritic mice $(P<0.01$ by Fisher's protected $t$ test in analysis of variance, $F \geq 6.13$ for proteinuria, and by chi-squared analysis for hematuria and semiquantitative morphometric data). 'Statistically significantly different from normal mice $(P<0.01$ by Fisher's protected $t$ test in analysis of variance, $F \geq 6.13$ for proteinuria, and by chi-squared analysis for hematuria and semiquantitative morphometric data). ** Significantly different from the before treatment value in the same group $(P<0.01$ by Fisher's protected $t$ test in analysis of variance, $F=17.65$ for proteinuria, and by chi-squared analysis for hematuria).
} 
with dextran developed hematuria and proteinuria as already described. Once again, hematuria and proteinuria persisted after $5 \mathrm{~d}$ of saline therapy, but were significantly reduced after $5 \mathrm{~d}$ of therapy with a combination of protease and dextranase (active enzymes, Table III). In contrast, the combination of inactivated protease and inactivated dextranase (inactive enzymes, Table III) had no significant effect, and mice treated with inactive enzymes showed significantly more hematuria and proteinuria than mice treated with active enzyme or normal control mice. Active but not inactive enzymes significantly reduced glomerular immune deposits of IgA, IgG, IgM, and $\mathrm{C} 3$, and mesangial hypercellularity and matrix expansion evident by light microscopy (Table III).

\section{Discussion}

The results presented here confirm earlier observations (9-11) that chronic immunization of mice with cationic dextran elicits hematuria and a mesangiopathic glomerulonephritis with prominent IgA in the glomerular immune deposits. The more frequent deposition of $\operatorname{IgG}$ admixed with the $\operatorname{IgA}$ and IgM within glomerular deposits is the only difference, one we consider minor, from the original description of the active IgA nephropathy model $(10,11)$. The therapeutic effect of exogenous enzymes on the clinical and pathological expression of IgA nephropathy in this murine model is clearly beneficial. Both dextranase and protease alone comparably reduced hematuria, glomerular dextran, and C3. Dextranase performed better than protease in reducing glomerular IgA and diminishing mesangial matrix expansion. On the other hand, protease was more effective than dextranase at reducing glomerular IgG and IgM, mesangial hypercellularity, and proteinuria. As discussed previously $(3,5)$, diminished proteinuria in proteasetreated animals cannot be ascribed to digestion of proteins in the circulation or in the urine. The combination of dextranase and protease diminished hematuria and proteinuria more effectively than either enzyme alone, and significantly reduced both mesangial matrix expansion and hypercellularity compared with saline or inactivated enzymes.

The present work lends further support to the concept that enzymes capable of degrading immune complexes in situ can ameliorate glomerulonephritis. Previously we noted reduction of glomerular immune complexes by nontoxic protease therapy, prevention and reversal of proteinuria, and reversal of established nephrotic syndrome in several different models of glomerulonephritis $(1,3,5)$; other results are in agreement $(2$, 4). In all these previous studies the antigen component of the immune complexes, as well as, of course, the antibody component, was protein in nature. In the current paper, we extend our previous observations by showing that cleavage of antigen alone, in this case a polysaccharide, or antibody alone can attenuate immune complex-induced glomerular injury. We further demonstrate for the first time that hematuria and mesangial expansion occurring in proliferative glomerulonephritis can also be diminished after enzymolysis of immune complexes in vivo. Finally, we offer additional evidence that the therapeutic effects of enzymes on immune complex glomerulonephritis are due to their capacity to degrade immune complexes locally in glomeruli rather than to some nonspecific effect since inactivated proteases and dextranase were ineffective at amelioration of urinary and histological abnormalities. Moreover, it is improbable that both proteases and dextranase would have similar nonspecific or indirect, yet therapeutically beneficial effects on such parameters as glomerular hemodynamics, serum complement or mononuclear phagocyte system function, for example.

The concept of dissolution of glomerular immune complex deposits in vivo was first espoused by Valdes et al., and more recently expanded upon by Wilson and Dixon, Mannik and Striker, and Haakenstad et al. (16-19), all of whom used excess antigen to solubilize glomerular immune deposits in systems where the antigen was known. Advantages of using enzymes rather than excess antigen to dissolve glomerular immune complexes are that knowledge of the relevant antigen is not required to achieve a therapeutic effect and that the antibody component of immune complexes, at least, will always be subject to proteolysis. Although not an issue in experimental glomerulonephritis where the antigen is known, there are few instances of glomerulonephritis in humans in which the antigen is known. We believe that nontoxic doses of exogenous enzymes potentially can be used to dissolve glomerular immune complexes in spontaneous human glomerulonephritis, a category of disease for which there is currently no effective therapy. The studies described here further support this concept, and additionally offer hope that in cases where the culprit antigen includes a polysaccharide component, even if of unknown identity, combination therapy with saccharolytic enzymes may be more effective than protease therapy alone.

Another use of the kind of therapeutic maneuvers used in this study is to probe the role of pathophysiologic mechanisms and specific mediators operative in glomerulonephritis. Along these lines, dextranase appeared to reduce mesangial matrix expansion more effectively than protease, whereas protease was more effective at reducing hypercellularity. These data suggest that the IgA or antigen components removed by dextranase are more closely coupled to matrix expansion, but IgG or IgM components removed by protease are more closely linked to proliferation. These considerations provide the basis for a testable hypothesis relating different components of glomerular immune deposits and the inflammatory response.

The differences in the effects of protease versus dextranase given individually are of interest. Although IgA may be more resistant to proteolysis than IgG or IgM, the failure of dextranase to diminish deposits of IgG and IgM in the active model is surprising. Indeed, if dextran were the only antigen involved in the deposited immune complexes, IgG and IgM would likely be dislodged effectively by the dextranase. In the passive model, induced by injection of immune complexes of dextran and IgM anti-dextran antibody in pure form, IgM deposits were reduced by dextranase. Hence, it is possible that the persistent IgG and IgM codeposits in the active model represent antibody specific for some antigenic component other than dextran, perhaps a polypeptide sensitive to protease but not dextranase. Anti-dextran antibody of all three major isotypes is demonstrable in sera of immunized mice, but we cannot exclude participation of other antigens. Indeed, we and others have proposed that the glomerular immune deposits in patients with IgA nephropathy consist of a mixture of distinct antigen/antibody complexes, and may include IgG and/or IgM anti-IgA rheumatoid factors as well as other specificities (reviewed in reference 7). Altered mononuclear phagocyte function and glomerular permselectivity initially induced by a pure dextran/anti-dextran system may promote deposition of unrelated immune complexes. However, that protease reduced 
dextran deposits within glomeruli in these experimental mice suggests that at least some of the IgG and IgM subject to removal by protease was bound to dextran. Perhaps the structure of the immune lattice within the glomerular deposits formed in the active model differs from that in the passive model such that dextranase digestion alone cannot liberate all $\mathrm{IgG}$ and IgM accessible to direct immunostaining in the former model but can in the latter. Without knowledge of the three-dimensional structure of the naturally forming mixed-isotype immune complexes or a complete list of the antigens deposited in the active model, these aspects cannot be interpreted fully.

Whatever the detailed composition of the deposits, it is clear that protease and dextranase, particularly in combination, can reduce immune deposits and functional and morphologic expression of glomerular injury in these models of IgA nephropathy. Hematuria, mesangial matrix expansion, and cell proliferation thus join proteinuria and quantity of immune deposits as disease parameters which can be attenuated by systemic administration of nontoxic doses of enzymes capable of cleaving immune complexes. This approach may prove useful in probing the relation between structure and function and between stimulus and response in glomerulonephritis, and holds promise as a future therapeutic strategy as well.

\section{Acknowledgments}

The authors are grateful to Nancy U. Nagy for technical assistance, and to Sara A. Cechner for typing the manuscript. The authors are also indebted to Dr. Ruth Siegel for use of her image analysis system.

This work was supported by National Institutes of Health grants DK-38544, AI-26449, and HL-37117, and a grant from the American Heart Association, Northeast Ohio Affiliate. L. Gesualdo is an R. H. "Mike" Mohrman Research Fellow of the Kidney Foundation of Ohio.

\section{References}

1. Nakazawa, M., S. N. Emancipator, and M. E. Lamm. 1986. Removal of glomerular immune complexes in passive serum sickness nephritis by treatment in vivo with proteolytic enzymes. Lab. Invest. 55:551-556.

2. Steffen, C., and J. Menzel. 1987. In vivo-abbau von immunkomplexen der niere durch oral applizierte enzyme. Wien. Klin. Wochenschr. 99:525-531.

3. Nakazawa, M., S. N. Emancipator, and M. E. Lamm. 1986.
Proteolytic enzyme treatment reduces glomerular immune deposits and proteinuria in passive Heymann nephritis. J. Exp. Med. 164:1973-1987.

4. Ohnishi, H. 1988. The effect of pepsin on autologous immune complex glomerulonephritis. Life Sci. 33:671-677.

5. Emancipator, S. N., R. B. White, and M. E. Lamm. 1988. Efficacy of proteases in reducing proteinuria and deposits in glomerulonephritis induced by cationic antigen is improved by targeting with avidin A. Kid. Int. 33:313a. (Abstr.)

6. D'Amico, G. 1987. The commonest glomerulonephritis in the world: IgA nephropathy. Quart. J. Med. 64:709-727.

7. Emancipator, S. N., and M. E. Lamm. 1989. IgA nephropathy: pathogenesis of the most common form of glomerulonephritis. $L a b$. Invest. 60:168-183.

8. Emancipator, S. N., G. R. Gallo, and M. E. Lamm. 1987. Animal models of IgA nephropathy. In IgA Nephropathy. A. R. Clarkson, editor. Martinus Nijhoff Publishing, Boston. 188-203.

9. Isaacs, K., and F. Miller. 1983. Antigen size and charge in immune complex glomerulonephritis. II. Passive induction of immune deposits with dextran-anti-dextran immune complexes. Am. J. Pathol. 111:298-306.

10. Isaacs, K., and F. Miller. 1982. Role of antigen size and charge in immune complex glomerulonephritis. I. Active induction of disease with dextran and its derivatives. Lab. Invest. 47:198-204.

11. Isaacs, K., and F. Miller. 1984. Dextran-induced IgA nephropathy. Contrib. Nephrol. 40:45-50.

12. Kunimitsu, D. K., and K. T. Yasunobu. 1970. Chymopapain B. Methods Enzymol. 19:244-252.

13. Sugiura, M., A. Ito, T. Ogiso, K. Kato, and H. Asano. 1973. Studies on dextranase: purification of dextranase from penicillium funiculosum and its enzymatic properties. Biochim. Biophys. Acta. 309:357-362.

14. Ikemura, H., and M. Inouye. 1988. In vitro processing of prosubtilisin produced in Escherichia coli. J. Biol. Chem. 263:1295912963.

15. Shapira, E., and R. Arnon. 1969. Cleavage of one specific disulfide bond in papain. J. Biol. Chem. 244:1026-1032.

16. Valdes, A. J., L. B. Senterfelt, A. D. Pollack, and F. Germuth. 1969. The effect of antigen excess on chronic immune complex glomerulonephritis. Johns Hopkins Med. J. 124:9-16.

17. Wilson, C. B., and F. J. Dixon. 1971. Quantitation of acute and chronic serum sickness in the rabbit. J. Exp. Med. 134:7s-19s.

18. Mannik, M., and G. E. Striker. 1980. Removal of glomerular deposits of immune complexes in mice by administration of excess antigen. Lab. Invest. 42:483-489.

19. Haakenstad, A. O., G. E. Striker, and M. Mannik. 1983. Removal of glomerular immune complex deposits by excess antigen in chronic mouse model of immune complex disease. Lab. Invest. 48:323-331. 